\title{
Fatores relacionados ao diagnóstico tardio do câncer de boca no estado da Paraíba - Brasil: relatos de pacientes portadores
}

\section{Factors related to diagnostic delay of oral cancer in the state of Paraíba - Brazil: subjects perspectives}

\author{
Paula Angela Souto Montenegro de Almeida CUNHA \\ Professora Adjunta - Universidade Federal da Paraíba - UFPB - João Pessoa - PB - Brasil.
}

Maria de Fátima Martins CATÃo

Professora Doutora - Programa de Pós-Graduação em Psicologia Social - Universidade Federal da Paraíba - UFPB - João Pessoa - PB - Brasil.

\section{Lino João da COSTA}

Professor Associado - Universidade Federal da Paraíba - UFPB - João Pessoa - PB - Brasil.

\begin{abstract}
Resumo
O Carcinoma Epidermoide (CE) da cavidade bucal, no Brasil, é uma patologia com incidência elevada, apresentando altas taxas de mortalidade e morbidade. O estágio da doença, no momento do diagnóstico caracteriza o mais importante fator de prognóstico. Neste estudo foram avaliados os fatores relacionados ao diagnóstico tardio desta patologia em pacientes no estado da Paraíba - Brasil, relatos e seu significado para estes pacientes. A amostra constou de 84 pacientes, diagnosticados no ambulatório do Serviço de Cabeça e Pescoço do Hospital Napoleão Laureano, em João Pessoa/PB. Foi realizada uma entrevista semi-estruturada com os portadores da doença, obtendo-se dados sócio-demográficos e as respostas que expressaram as razões da procura tardia do serviço de saúde. Identificou-se pela análise de conteúdo das respostas os significados do diagnóstico tardio e foram agrupados de acordo com seu conteúdo em: 1. Sabia da lesão, mas só procurou, quando incomodou; 2. Sabia da lesão, procurou um serviço de saúde e foi diagnosticado e tratado inadequadamente; 3. Não sabia da existência da lesão, procurou o serviço de saúde, quando incomodou; 4. Medo e negação da doença, temor do enfrentamento da doença; 5. Indisponibilidade de tempo por trabalho e dificuldade de acesso. Pela análise de conteúdo, o medo da doença, a desinformação e as condições sociais desfavoráveis representaram um desestímulo à procura do tratamento.
\end{abstract}

\section{UNITERMOS}

Neoplasias bucais; carcinoma epidermoide; diagnóstico bucal.

\section{INTRODUÇÃO}

Nos últimos anos, as características da população brasileira mudaram consideravelmente. A sociedade que foi por muito tempo baseada na economia rural, a partir da década de 40 foi se transformando em uma sociedade de caráter fortemente urbano, com mais de $80 \%$ da população atualmente vivendo nas cidades. Esse processo levou a uma mudança nos indicadores de saúde, tendo em oposição ao declínio da mortalidade infantil, um substancial aumento da expectativa de vida. Até a metade do século XX, a expectativa de vida estava abaixo dos 50 anos, mas, no final de
2000, alcançou um pouco mais que 68 anos e, neste momento ultrapassa os 70 anos.

$\mathrm{O}$ crescimento da incidência do câncer está relacionado ao envelhecimento da população. O perfil do câncer no Brasil vem acompanhando o perfil observado em países desenvolvidos. As mudanças refletem o processo de urbanização e a ampliação do acesso à informação. "O câncer está presente em todas as sociedades, mas em cada uma delas a doença apresenta um perfil específico. Num país com as dimensões e diferenças que o Brasil apresenta, as especificidades se revelam também entre as regiões e entre as capitais ${ }^{9}$. 
Mais da metade dos novos casos de câncer que surge anualmente ocorre em países em desenvolvimento, e as classes sociais menos privilegiadas são as que apresentam maiores taxas da doença ${ }^{19}$.

As taxas de mortalidade para o câncer de boca e orofaringe, em algumas áreas no Brasil, estão entre as mais elevadas no mundo. As estimativas do Instituto Nacional do Câncer (INCA) para 2008 são de 10.380 novos casos entre os homens e 3.780 entre as mulheres. Na região Nordeste, as estimativas das taxas brutas de incidência por 100.000 são de 1.530 novos casos para os homens e 970 para as mulheres. Na Paraíba, para 100 mil habitantes as estimativas, de câncer da cavidade bucal, são de 110 casos novos entre os homens e de 80 entre as mulheres ${ }^{9}$.

Para Laemmel et al. ${ }^{13} 95 \%$ dos casos de câncer bucal ocorrem em pacientes de todas as etnias com mais de 40 anos de idade, com variações relacionadas apenas ao consumo de tabaco e álcool.

Segundo Kowalski ${ }^{11}$, as principais causas das neoplasias da boca são atribuídas a influências ambientais, destacando-se àquelas relacionadas aos hábitos pessoais, à atividade profissional e ao meio em que a pessoa vive. Já está bem estabelecida a ação sinérgica e a ligação entre o consumo de tabaco e álcool e desenvolvimento de CE da cavidade bucal $1^{14,17,21,25,28}$.

O principal determinante de um mau prognóstico é o estágio da doença no momento do diagnóstico. Gervásio et al. ${ }^{7}$ analisando dados referentes ao estadiamento em pacientes com câncer bucal constataram que, ao serem atendidos pela primeira vez em serviços especializados, em torno de $80 \%$ dos casos encontravam-se em fase avançada.

A importância do diagnóstico precoce do câncer bucal é inquestionável; diagnóstico tardio resulta em doença avançada, em uma sobrevida reduzida e em alta taxa de morbidade e mortalidade.

Apesar da taxa de incidência ser variável de um país para outro, a mortalidade é quase uniforme, em torno de 50 a $60 \%$ desses pacientes vão a óbito em estatísticas estáveis por várias décadas. A OMS previu um aumento mundial contínuo em números absolutos de pacientes com câncer bucal, estendendo essa tendência para as próximas décadas ${ }^{21}$.

Considerando que muitos dos pacientes com câncer bucal que se apresentam para a primeira consulta em um serviço especializado estão com a doença em fase avançada, é fundamental identificar os fatores que contribuem para que essa situação permaneça e se perpetue. Este estudo tem como objetivo avaliar as razões pelas quais ocorre uma procura tardia do serviço de saúde dos pacientes portadores de Carcinoma Epidermoide para o diagnóstico da doença.

\section{Material e Métodos}

A pesquisa foi realizada no Serviço de Cirurgia de Cabeça e Pescoço do Hospital Napoleão Laureano, em João Pessoa, PB, Brasil. Este hospital é referência em oncologia no estado da Paraíba, atendendo a 223 municípios do estado. O estudo desenvolvido foi prospectivo e constou de 84 pacientes de ambos os sexos, maiores de 18 anos, portadores de CE, na cavidade bucal.

Foi realizada uma entrevista individual com os pacientes atendidos pela primeira vez no ambulatório por profissional médico. Os pacientes com hipótese diagnóstica de $\mathrm{CE}$ foram submetidos a uma biópsia incisional e entrevistados pelo profissional dentista, especialista em estomatologia. Na entrevista foram coletados dados pessoais sobre idade, sexo, raça, profissão, hábitos (tabagismo e etilismo), o tempo em meses do encaminhamento até um serviço especializado, e a pergunta aberta: "porque não procurou o serviço de saúde antes?"

Foram categorizadas as respostas à questão aberta da entrevista semi-estruturada: Por que não procurou o Serviço de Saúde antes?, a qual teve por objetivo identificar os significados que levaram os indivíduos a procurar ajuda profissional quando o tumor na maior parte das vezes era tão avançado resultando em um diagnóstico tardio. Como procedimento de análise dos dados, utilizou-se da Análise de Conteúdo Temática $^{4,24,6}$. Foi usado um plano de análise aplicada de acordo com as seguintes etapas conforme Vala ${ }^{26}$ : constituição de um corpus; definição de categorias; definição de unidades de análises, quantificação dos dados e interpretação dos resultados.

\section{Resultados e Discussão}

\section{Características biodemográficas dos pacientes}

As características demográficas e de hábitos dos pacientes investigados foram: sexo, grupo étnico, faixa etária, educação, profissão do paciente, tabagismo e etilismo. Dentre os 84 integrantes da amostra, 70,2\% são do sexo masculino, e $29,8 \%$, do sexo feminino, indicativo de que o quantitativo dos indivíduos do sexo masculino foi estatisticamente maior que do sexo 
feminino. Percebe-se uma distribuição equilibrada quanto ao grupamento étnico, com $47,6 \%$ de indivíduos brancos e $52,4 \%$ não brancos, com diferença não significativa.

Em relação à idade, $40,5 \%$ dos indivíduos tinham de 30 a 60 anos, e 59,5\%, acima de 60 anos. A idade média dos indivíduos foi de 64 anos com um erropadrão de 1,5 anos e intervalo de confiança $95 \%$ de $61,3<\mu<67,4$ anos. O respondente mais velho tinha 92 anos, e o mais novo, 30 anos. A grande parte desses pacientes $(75 \%)$ era analfabeta, e $25 \%$ tinham o ensino fundamental incompleto ou outros. O número de indivíduos analfabetos foi significativamente maior do que aqueles de nível fundamental e outros. Com relação à profissão do paciente, $63,1 \%$ dos indivíduos responderam que eram agricultores e $36,9 \%$ informaram que eram donas de casa, motorista e outras profissões, com uma diferença significativa equivalente a $26,2 \%$.
Os dados refletem um maior número de pacientes que fuma e ingere bebida alcoólica $(79,8 \%)$, aqueles que só fazem uso do fumo perfazem $15,5 \%$, aqueles que só ingerem bebida alcoólica $1,2 \%$, e os abstêmios um total de 3,6\%. O consumo conjunto de álcool e tabaco foi bastante elevado e, segundo Wildt et al. ${ }^{28}$, McCann et al. ${ }^{14}$, Sciubba ${ }^{21}$, McLeod et al. ${ }^{17}$, Tromp et al. ${ }^{25}$, já está bem estabelecida a ação sinérgica e a ligação entre o consumo de tabaco e álcool e desenvolvimento de $\mathrm{CE}$ da cavidade bucal.

\section{Dados referentes à análise do conteúdo das respostas à pergunta: Por que não procurou o serviço de saúde antes?}

$\mathrm{Na}$ avaliação desta etapa foram categorizadas as respostas à questão aberta da entrevista semiestruturada, e dela foram apreendidas 05 categorias (Tabela 1).

Tabela 1 - Frequência de pacientes/respostas à questão aberta: Por que não procurou o serviço de saúde antes?

\begin{tabular}{|c|c|c|}
\hline Categorias & $\begin{array}{c}\text { Frequência } \\
\text { Pacientes }\end{array}$ & $\%$ Pacientes \\
\hline Sabia da lesão, mas só procurou o serviço de saúde, quando incomodou. & 23 & 27,4 \\
\hline Sabia da lesão, procurou o serviço de saúde e foi diagnosticada inadequadamente. & 13 & 15,5 \\
\hline Não sabia da lesão, procurou o serviço de saúde, quando incomodou & 21 & 25,0 \\
\hline Medo e negação da doença & 12 & 14,3 \\
\hline Condição social impeditiva & 15 & 17,9 \\
\hline Total & 84 & \\
\hline
\end{tabular}

\section{1 - Sabia da lesão, mas só procurou, quando incomodou}

Esta foi a categoria com maior número de respondentes. Pode-se inferir que pacientes toleram a convivência com o tumor por negligência com eles mesmos e também pela evolução assintomática deste tumor.

Esta resposta foi compreendida como consciência da presença da lesão, tolerância e despreocupação com ela, até quando começa o sofrimento, conforme pode ser observado nas frases seguir.

"Não procurei, porque a ferida sumia e voltava; quando começou a incomodar, procurei o médico.". "Era muito pequena, não incomodava, só fui ao médico quando cresceu", "Não doía, depois começou a incomodar arder, procurei o médico", "Pensava que não era nada demais, queria melhorar", "Pensei que ia ficar bom, quando piorou, resolvi vir ao médico".

A partir dos relatos dos pacientes, pode-se admitir que eles tinham uma doença, sem saber da sua gravidade. Como o CE bucal no início, em geral é assintomático, a convivência, enquanto a lesão é pequena, é perfeitamente aceita pelo paciente. O sentimento que perpassa o significado da doença é sempre "pensava que não era nada demais, que iria melhorar" (...). O paciente aceita a convivência, até o momento em que os transtornos provocados por um tumor em estágio avançado começam a modificar o seu cotidiano; quando o simples ato de comer e beber água passa a ser exercido com dificuldade, é que ele pensa em procurar ajuda. Observa-se, entretanto, a consciência da lesão, e não do câncer. 
A consciência da presença da lesão e sua tolerância representam, na base teórica, o atraso do diagnóstico por parte do paciente. Tromp et al..$^{25}$ observaram que, entre as diferentes formas de retardo do diagnóstico, aquela que se refere ao paciente parece ser a mais importante em relação ao tamanho do tumor. Para Holmes et al. ${ }^{8}$, pacientes de risco, isto é, aqueles que apresentam alto consumo de álcool e fumo, não se dispõem a visitar regularmente o dentista e, na maioria das vezes, negligenciam um tumor presente na boca. É na fase sintomática que normalmente o paciente procura ajuda, segundo Amir et al. ${ }^{3}$. Afirmam ainda estes autores que o tamanho do tumor é o sinal de alerta para o paciente e para o profissional. Em estudo realizado por Khoo et al. ${ }^{10}$, foi demonstrado que um grande atraso no diagnóstico foi causado pelo paciente, resultando no estágio avançado da doença e nas baixas taxas de sobrevida em 5 anos. Para McGurck et al. ${ }^{16}$, os sintomas não estão relacionados com o tamanho do tumor. A explicação mais plausível, segundo os autores, seria que, em tumores da região de cabeça e pescoço, o início dos sintomas independe do estágio do tumor, de forma que um grande tumor da cavidade bucal pode ser assintomático.

\section{2 - Sabia da lesão, procurou um Serviço de Saúde e foi diagnosticado e tratado inadequadamente}

Treze indivíduos na categoria 2 , nota-se, a importância da suspeita dos sinais de malignidade por parte do profissional que primeiro atende esses pacientes.

"Disse que não era nada, há 2 anos, aí depois apareceu um caroço, fui para outro médico que me mandou para João Pessoa- PB. " "Procurei um médico, mas o médico mandava de um para outro e nada resolvia." "Procurei, assim que senti a garganta inflamada, foi quando o médico disse que era uma lesão e encaminhou para Sousa-PB." "Fui várias vezes procurar o médico em Caruaru-PE e em Recife -PE, quando a ferida era pequena, já faz uns 6-8 meses que ando, acho que foi um dente." "Procurei em Nova Cruz- RN, mas o médico só passava pomada e não sarava, quando vim morar com minha filha ela me levou a um médico em Santa Rita-PB." "Procurei o médico que passou medicação que não deu resultado, até mostrar ao cardiologista que me mandou para o dentista"
Pode-se observar que houve a procura do Serviço de Saúde, todavia este não ofereceu ao paciente o tratamento adequado. Os relatos apreendidos nesta categoria tendem a mostrar que o paciente tinha consciência da lesão, e logo que lhe foi possível, procurou ajuda, o que não significou que todos os pacientes que tiveram esta fala chegaram ao ambulatório do Serviço de Cabeça e Pescoço com a doença em estágio precoce. O significado de uma fala como "assim que notei, procurei o dentista (...)" mostra o conceito elaborado acerca das implicações de uma possível gravidade da doença, o que não aconteceu nos relatos da categoria citada anteriormente.

Há uma relação entre o diagnóstico tardio e a má orientação do profissional que o atendeu. A consciência da presença da lesão, a preocupação com relação a ela e a procura por um serviço de saúde, onde é feito um diagnóstico inadequado, vistos nos relatos deste estudo corroboram com estudo de Gervásio et al. ${ }^{7}$, que relacionam o diagnóstico tardio ao profissional que não consegue suspeitar da malignidade da lesão. Para Alho et al. ${ }^{1}$, um diagnóstico mal conduzido, na primeira consulta, pode dar ao paciente um falso sentimento de segurança que o levará a retardar uma segunda consulta. Tromp et al. ${ }^{25}$ observaram que a não-suspeita de malignidade de uma lesão por parte do profissional estava associada ao retardo do paciente em procurar ajuda em uma segunda consulta.

Em estudo realizado por Wildt et al. ${ }^{28}$, o diagnóstico tardio relacionado ao profissional era maior em pacientes que apresentavam tumores pequenos que em pacientes com tumores grandes. Allison et al. ${ }^{2} \mathrm{e}$ Carvalho et al..$^{5}$ também encontraram relação entre o diagnóstico tardio por parte do profissional e o estágio avançado do tumor. Segundo Khoo et al. ${ }^{10}$, o retardo do diagnóstico pelo profissional leva a um tratamento inapropriado tal como medicação antibiótica ou corticóides e exodontias.

\section{3 - Não sabia da existência da lesão procurou o profissional, quando incomodou}

Nesta categoria, 21 pacientes responderam, perfazendo $25,0 \%$ da amostra. Percebe-se, neste caso, o pouco nível de informação que o paciente demonstra e também um comportamento preventivo longe do minimamente ideal, além da não-percepção da lesão e desconhecimento sobre a doença

"Senti uma dor debaixo da chapa ai fui olhar o que era e vi uma peladura." "Não notei, 
só comecei a notar quando chupava laranja porque ardia ai procurei o dentista." "Não vi a ferida, quando não pude mais comer foi que vi a ferida." "Me queixava de dor de garganta e o dente doendo mas nunca procurei o médico antes de aparecer o caroço." "Não sabia que tinha uma ferida ai, foi de repente".

Compreende-se, nesta categoria, o desconhecimento do paciente sobre o tipo de sua doença, pois, como já foi observado o CE bucal no início. O baixo nível de escolaridade, juntamente com o pouco esclarecimento deste paciente, não freqüentador regular de um serviço odontológico, leva-o a não pensar que uma ferida possa ser um câncer, assim só percebe sua presença, a partir do momento em que incomoda. A fala "teimoso, achava que era um dente, não queria vir para João Pessoa, depois pedi para vir para o médico" (...) demonstra a falta de informação e desconhecimento. A imagem elaborada é de que não se sabia da existência da "ferida" na boca, portanto associa-se ao mais óbvio, que seria um dente doendo, ou "... foi de repente" algo que apareceu no momento. Nos casos de não-consciência da lesão, observam-se dois tipos de compreensão: não se percebe a lesão, devido à localização do tumor, e se desconhece a doença.

A não-percepção da lesão e a falta de informação sobre a doença, salientes nos relatos desta categoria, são fatores que, indubitavelmente, contribuem para um estágio avançado do tumor no momento do diagnóstico. Para Tang Ho et al. ${ }^{23}$, o acesso difícil a um serviço de saúde, a ausência de inspeção da cavidade bucal por parte do profissional e do paciente e a falta de sinais alarmantes relacionados ao tumor fazem com que o paciente não perceba a lesão. Rubright et al. ${ }^{20}$ observaram que, dos pacientes examinados em seu estudo, o desconhecimento dos sinais e dos sintomas do câncer bucal foi relatado por $87 \%$ deles. Amir et al. $^{3}$ observaram que $24 \%$ dos pacientes, quando perguntados sobre a interpretação de seus sintomas, não consideraram preocupantes, interpretando-os como uma simples infecção.

\section{4 - Medo e negação da doença e medo de enfrentamento da doença}

Esta categoria incluiu $14,3 \%$ dos respondentes, perfazendo 12 pacientes. Nela, é notável o temor das conseqüências que a doença poderá acarretar - o sofrimento, a dor, a mutilação - então, é melhor utilizar a estratégia da negação. A expressão do temor do sofrimento que a doença pode causar estão expressos nas seguintes afirmações.

"Porque não queria vir". "Porque não quis" "Eu não queria procurar o médico" "Nunca disse à família" " Eu não queria vir ao médico, e a família não queria contrariar-" "Não disse a família" "Já fazia tempo que tinha outra ferida" "Não queria que a família me acompanhasse, no primeiro tumor tratei escondido agora não conseguia mais comer e tinha dor, procurou o médico" "Nunca mostrei a boca à família, mas, com caroço no pescoço, a família levou ao médico" "Tinha medo, não quis vir antes" "Não quis vir ao médico" "Tinha medo de ficar no hospital"

Nesta categoria, figuram imagens de negação perpassada pelo medo de algo conhecido como desagradável, doloroso, sem solução. Então, é melhor não compartilhar com ninguém esse sentimento, escondendo a doença, evitando o sofrimento da família. O significado do tratamento certamente parece ao paciente algo drástico e negativo que vai fazê-lo sofrer. A dificuldade de enfrentamento o leva a utilizar, como estratégia, a ocultação de sua doença tanto da família como do profissional que poderia tratá-lo. $\mathrm{Na}$ literatura revisada não foram encontradas informações com relação a esta categoria.

\section{5 - Indisponibilidade de tempo por trabalho e dificuldade de acesso}

Esta categoria envolve aspectos relativos às dificuldades impostas a estes pacientes pela realidade socioeconômica do país e as condições sociais de sobrevivência. É a terceira categoria em número de respostas, com 15 pacientes inserindo-se neste conteúdo, perfazendo $17,9 \%$ do total.

"Não tinha tempo". "Descuido e por causa do trabalho" "Não tinha tempo, só tenho folga na segunda feira" "Trabalhando todo dia, não tinha tempo" "Notou uma coceirinha, voltei a trabalhar e não tive mais tempo, até que começou a crescer" "Não vim antes, porque o vereador encarregado não providenciou" "Falta de recurso" "Era complicado vir" "Moro longe não tenho condições" "Porque é longe" "Sem condições de vir, não tenho dinheiro" "Não tinha com quem vir, moro só". 
Emerge, nesta categoria, os fatores alheios à vontade do paciente, impedindo-o de cuidar de um problema que, por falta de "tempo" e devido a um contexto social difícil, vai deixando que progrida. Observa-se uma naturalização da conjuntura social, não há questionamento diante deste cenário de pobreza e desassistência. Não há nenhum estranhamento diante de sua condição de vida, que não é natural, mas algo historicamente construído. Percebe-se uma apatia e uma aceitação desta realidade adversa.

O diagnóstico tardio tem sido freqüentemente associado aos baixos indicadores sociais e ao grupo étnico em vários estudos ${ }^{27,15}$.

Kowalski e Carvalho ${ }^{12}$ afirmaram que a população de baixo nível socioeconômico apresentou menores taxas de sobrevida que o restante da população, baseado na diferença do estágio clínico do tumor desses indivíduos, devido, em parte, à falta de educação, ausência de comportamento preventivo e demora em procurar serviços de saúde, à deficitária assistência médica. O complexo e difícil sistema social do país e a dificuldade em procurar ajuda resultam em doença avançada e pior prognóstico.

$\mathrm{Na}$ amostra, $66,7 \%$ das repostas relacionaram-se ao diagnóstico tardio por parte do paciente, incluindo razões que dizem respeito ao desconhecimento, ao medo e à negligência com a saúde. O restante dos relatos compreendeu um total de $33,4 \%$ e foi relacionado ao profissional que atendeu o paciente na primeira consulta e à condição socioeconômica.

Como pode se observar, o significado da doença e o diagnóstico tardio em relação ao paciente no período que antecede a busca do serviço de saúde se apresentaram nas 5 categorias que se organizaram em um espaço multi-dimensional: em nível de informação, de sentimentos e de condições sociais.

Segundo Pelag et al. ${ }^{19}$, a imagem simbólica negativa do câncer contribui para a insuficiência de iniciativa da população em cuidados preventivos. Isso gera um tempo prolongado e perigoso entre os primeiros sinais e a consulta médica; em decorrência, um pior prognóstico para o paciente, para os familiares e para a sociedade. Devido ao fato de o diagnóstico ser tardio, o paciente inicia seu tratamento em estádio avançado, limitando as possibilidades de tratamento.

Fica claro, nos relatos dos pacientes, uma falta de consciência do caráter saudável do comportamento preventivo, já que pode haver mudança de prognóstico, caso o câncer seja detectado em estágio precoce.

Os resultados obtidos enfatizam a necessidade de programas de educação continuada da população e dos profissionais no sentido da identificação de sinais precoces da doença principalmente em pacientes considerados de risco.

\section{Conclusão}

Através da análise de conteúdo temática realizada neste trabalho, concluiu-se que:

Pacientes portadores de $\mathrm{CE}$ da boca não procuram rapidamente um serviço de saúde uma vez que suas lesões são assintomáticas em estágios precoces.

O medo da doença, a desinformação e as condições sociais desfavoráveis representaram um desestímulo à procura do tratamento.

\begin{abstract}
Oral squamous cell carcinoma in Brazil represents a pathology with a high level of incidence, a high mortality rate and morbidity, making the stage of the illness, at the moment of diagnosis, the most important factor in the prognosis of this type of tumor. Factors related to late diagnosis of oral cancer have been analyzed in the state of Paraíba through speeches and their significances in patients with this pathology. The sample consisted of 84 patients with squamous cell carcinoma in the oral cavity diagnosed at the Head and Neck Division at Napoleão Laureano Hospital, in Joao PessoaPB. A semi-structured interview has been realized from which social and demographic data and responses by patients who expressed their reasons for searching for the late medical help have been obtained.The reasons of the late diagnosis has been identified by the words of the patients, grouping them according to thematic categories: 1 . The patient was unaware of the injury but looked for help only when it became unconfortable; 2 . The patient was aware of the injury, looked for help but was diagnosed and treated inappropriately; 3 . The patient was aware of the injury and looked for help when it became unconfortable; 4 . Fear and denial towards the disease, afraid to face their condition; 5. Lack of time due to working hours and transportations difficulties. The results of the interview show that, fear of the disease, lack of information and poor socio-economic conditions unmotivated patients to seek out treatment.
\end{abstract}

\title{
UNITERMS
}

Oral neoplasm; squamous cell carcinoma; oral diagnosis. 


\section{REFERÊNCIAS}

1. Alho OP, Teppo H, Mantyselka P, Kantola S. Head and Neck cancer in primary care: presenting symptoms and the effect of delayed diagnosis of cancer cases. CMAJ. 2006; 174(6):779-84.

2. Allison P, Franco E, Feine J, Blanc M. The role of professional diagnostic delays in the prognosis of upper aerodigestive tract carcinoma. Oral Oncol. 1998; 34(2):147-53.

3. Amir Z, Kwan SY, Landes D, Feber T, Williams SA. Diagnostic delays in head and neck cancers. Eur J Cancer Care. 1999;8(4):198-203.

4. Bardin L. L'analise de contenu. Paris: Presses Universitaire de France; 1977.

5. Carvalho AL, Pintos J, Schlecht NF, Oliveira BV, Fava AS, Curado MP. Predictive factors for diagnosis of advanced-stage squamous cell carcinoma of head and neck. Arch Otolaryngol Head Neck Surg. 2002; 128(3):313-8.

6. Catão F. Projeto de Vida em construção: na exclusão/ inserção social. João Pessoa: UFPB/ Universitária; 2001

7. Gervásio OLAS, Dutra RA, Tartaglia SMA, Vasconcelos WA, Barbosa AA, Aguiar MCF. Oral squamous cell carcinoma: A retrospective study of 740 cases in brazilian population. Braz Dent J. 2001;12(1):57-61.

8. Holmes JD, Dierks EJ, Homer LD, Potter BE. Is detection of oral and oropharygeal squamous cancer by a dental health care provider associated with a lower stage at diagnosis?. J Oral Maxillofac Surg 2003;61(3):285-291.

9. Instituto Nacional do Câncer. Estimativas da incidência e mortalidade por câncer no Brasil. [acesso 3 jul 2008]. Disponível em <http://www. inca.gov.br/estimativas/2008.

10. Khoo SP, Shanmuhasuntharam P, Mahadzir WM, Tay KK, Latif A, Nair $\mathrm{S}$. Factors involved in the diagnosis of oral squamous cell carcinoma in Malaysia. Asia Pac J Public Health. 1998;10(1):49-51.

11. Kowalski LP. Carcinoma da Boca: epidemiologia, diagnóstico e tratamento. Acta AWHO. 1991; 10(3):128-34.

12. Kowalski LP, Carvalho AL. Influence of time delay and clínical upstaging in the prognosis of head and neck cancer. Oral Oncol. 2001; 37(1):94-8.

13. Laemmel A, Capella NM, Teixeira GV. Câncer de boca, um problema crescente e alarmante no nosso meio. ACM arq Catarin med. 1995; 24(4):20-2.

14. Mccann MF, Macpherson LM, Gibson J. The role of the general dental practitioner in detection and prevention of oral cancer: a review of the literature. Dent Update. 2000; 27(8):404-8.

15. McDonald S, McLeod U, Campbell NC, Weller D, Mitchel E. Sistematic review of factors influencing patient and practitioner delay in diagnosis of upper gastrointestinal cancer. Br J Cancer, 2006;94(9):1272-80.

16. McGurck M, Chan C, Jones J, O'regan E, Sherriff M. Delay in diagnosis and its effect on outcome in head and neck cancer. Br J Oral Maxillofac Surg. 2005;43(4):281-4.
17. McLeod NM, Saeed NR, Ali EA. Oral cancer: delay in referral and diagnosis persist. Br Dent J. 2005;198(11):681-4.

18. Molina L, Dalben I, Luca L. Análise das oportunidades de diagnóstico precoce para as neoplasias malignas de mama. Rev Assoc Med Bras. 2003; 49(2):185-90.

19. Pelag DM, Pasquini R, Medeiros CR, Bitencourt MA, Moura GL. O câncer e sua representação simbólica. Psicol Cienc Prof. 2004; 24(2):120-33.

20. Rubright WC, Hoffman HT, Lynch MD, Kohout FJ, Robinson RA, Graham S, et al. Risk factors for advanced stage oral cavity cancer. Arch Otolaryngol Head Neck Surg. 1996; 122(6):621-6.

21. Sciubba JJ. Oral Cancer: The importance of early diagnosis and treatment. Am J Clin Dermatol 2001;2(4):239-51.

22. Sobin LH, Wittekind C. TNM: classificação dos tumores malignos. 5 ed. Rio de Janeiro: INCA; 1997.

23. Tang HO, Zahurak M, Koch WM. Prognostic significance of presentation-to-diagnosis intervals in patient with oropharyngeal carcinoma. Arch Otolaryngol Head Neck Surg. 2004; 130(1):45-51.

24. Triviños ANS. Pesquisa Qualitativa. Introdução à Pesquisa em Ciências Sociais. São Paulo: Atlas; 1987.

25. Tromp MD, Rbrouh X, Hordjik GJ, Winnubst JAM, Leeuw RJ. Pacient and tumor factors associated with advanced carcinomas of head and neck. Oral Oncol. 2005; 41(3):313-9.

26. Vala J. Análise de Conteúdo. In: Silva AS, Pinto JM, orgs. Metodologia em Ciências Sociais. Porto: Ed Apontamentos; 1986. cap. IV, p. 101-113.

27. Vineis P, Fornero G, Magnino GR, Ciconne G. Diagnostic delay, clínical stage and social class: a hospital based study. J Epidemol Community Health. 1993;47:229-31.

28. Wildt J, Bundgaard T, Bentzen SM. Delay in the diagnosis of squamous cell carcinoma. Clin Otolaryngol Allied Sci. 1995, 20(1):21-5.

Recebido em 13/04/2009

Aprovado em 07/04/2010

Correspondência:

Paula Angela Souto Montenegro de Almeida Cunha Endereço: Av. Tabelião José Ramalho Leite, 1568 - Cabo Branco

CEP 58.045-230

João Pessoa - PB

e-mail: paulasmac@yahoo.com.br 